\title{
PERENCANAAN PONDASI TIANG PANCANG GEDUNG PASCA SARJANA FAKULTAS TEKNIK UNIVERSITAS KADIRI
}

\author{
Rizaludin $^{* 1}$, Sigit Winarto ${ }^{2}$, Ahmad Ridwan ${ }^{3}$. \\ ${ }^{1,2,3}$ Fakultas Teknik, Universitas Kadiri. \\ email : *1 rizaludin474@gmail.com, ${ }^{2}$ sigit.winarto@unik-kediri.ac.id , \\ 3ahmad_ridwan@unik-kediri.ac.id .
}

\begin{abstract}
The foundation is a part of the structure that functions as a support for the building and distributes the burden on it (upper fabric) or the soil layer with a stable enough carrying capacity. In planning the foundation for a structure can use several types. The selection of the foundation to be used based on the weight of the building. The construction of the $C$ story building seven-story University requires a strong foundation. The pile foundation was chosen because it was relatively fast, easy, and yielded hard soil at $5.6 \mathrm{~m}$. In this calculation, three methods as a Trofimankove method and the Meyerhoff method and the General Method Method. Pile foundation planning has a planned load of Qu 231 Ton. The calculation of the three ways obtained more efficient results, namely the count with a Meyerhoff method equal to 82.21. The number of single piles that are close to one pile cap is four poles, so the calculation formula of the Pall piles group is 232.82 tons. Thus it can be concluded that Pmax <Pall 231 Ton <232.82 Ton, which means that it meets the requirements.
\end{abstract}

Keywords : Pile Foundation, Trofimankove Method, Meyerhoff Method, General Way.

\begin{abstract}
Abstrak
Pondasi adalah bagian struktur yang berfungsi sebagai penopang bangunan dan menyalurkan beban diatasnya (upper structure) atau lapisan tanah yang memiliki daya dukung yang cukup kuat . Dalam merencanakan pondasi untuk suatu struktur dapat menggunakan beberapa macam tipe pondasi. Pemilihan pondasi berdasarkan fungsi bangunan atas yang akan dipikul oleh pondasi tersebut, berdasarkan beban dan beratnya bangunan atas kedalaman tanah dimana bangunan tersebut didirikan. Pembangunan gedung $\mathrm{C}$ berlantai 7 Universitas Kadiri memerlukan pondasi yang kuat. Pondasi tiang pancang dipilih karena pekerjaan relatif cepat, mudah dan hasil sondir tanah keras pada 5,6 m. Pada perhitungan ini digunakan tiga metode yaitu metode Trofimankove dan metode mayerhoff serta Metode cara Umum. Perencanaan pondasi tiang pancang memiliki beban rencana sebesar Qu 231 Ton. Dari perhitungan ketiga metode didapat hasil yang lebih efisien yaitu pada perhitungan dengaan metode mayerhoff yaitu sebesar 82,21. Jumlah tiang tunggal yang mendekati pada satu pile cap adalah 4 tiang, sehingga diperoleh dari rumus perhitungan Pall tiang kelompok 232,82 Ton. Dengan demikian dapat disimpulkan Pmaks < Pall 231 Ton <232,82 Ton, yang artinya memenuhi syarat.
\end{abstract}

Kata Kunci : Pondasi Tiang Pancang, Metode Trofimankove, Metode Mayerhoff, Cara Umum. 


\section{PENDAHULUAN}

Pondasi adalah bagian struktur yang berfungsi sebagai penopang bangunan [1][2] dan menyalurkan beban diatasnya (upper structure) [3][4][5], atau lapisan tanah yang memiliki daya dukung yang cukup kuat, [6][7]. Pondasi dapat di artikan lagi sebagai bagian paling bawah dari suatu konstruksi yang kuat, [8][9][10] dan stabil (solid) [11]. Dalam merencanakan pondasi untuk suatu struktur dapat menggunakan beberapa macam tipe pondasi, [12]. Pemilihan pondasi berdasarkan fungsi bangunan atas yang akan dipikul oleh pondasi tersebut, berdasarkan beban [13][14] dan beratnya bangunan atas kedalaman tanah dimana bangunan tersebut didirikan, [11]. Saat ini makin banyak didirikan gedung-gedung berukuran besar [15], terutama di konstruksi Surabaya, [16].

Pondasi tiang pancang merupakan salah satu jenis pondasi dalam. Pondasi tiang pancang berfungsi sebagai penyalur beban pondasi melewati lapisan tanah dengan daya dukung rendah kelapisan tanah yang mempunyai kapasitas daya dukung tinggi yang relative cukup dalam di banding pondasi dangkal. Daya dukung tiang pancang diperoleh dari daya dukung ujung (End Bearing Capacity) daya dukung geser atau selimut (fiction bearing capacity) .Sehubungan dengan pembangunan ini, kerap kali dalam menentukan jenis kondisi bangunan timbul masalah - masalah [17][18][19], yang diakibatkan oleh kondisi lapisan tanahnya [20] di Universitas Kadiri, Kediri. Hal ini terjadi pula pada PERENCANAAN PONDASI TIANG PANCANG GEDUNG PASCA SARJANA FAKULTAS TEKNIK UNIVERSITAS KADIRI. Pada waktu diadakan penyelidikan tanah keras letaknya tidak terlalu dalam dari permukaan tanah.

\section{METODOLOGI PENELITIAN}

\subsection{Pengumpulan Data.}

Adapun metode yang digunakan penulis untuk pengumpulan data ini diperoleh dari hasil survey lapangan secara langsung dan dari instansi yang terkait. Data-data yang dimaksudkan sebagai berikut :

A. Data Primer.

Data Primer merupakan data yang dikumpulkan langsung di lokasi pengamatan. Data tersebut ialah Pengukuran pada lokasi atau letak bangunan Kondisi atau sistem struktur dibangunan sekitar, Data tanah hasil penyelidikan tanah, menggunakan tes Sondir, Metode Instrumen (Alat Bantu) seperti handphone, alat pengukur, alat tulis, guna untuk mendapatkan data-data ataupun informasi terkait sebagai bentuk pengumpulan data pada saat berlangsungnya proses observasi dilapangan. 
B. Study Literatur.

Study literatur adalah proses pengumpulan data dari berbagai sumber referensi terkait dengan pondasi, jurnal, dan penelitian yang telah dilakukan yang berkaitan dengan pondasi. Data yang didapat dari studi literatur ini akan digunakan sebagai acuan untuk membuat penelitian.

C. Metode Observasi Dan Pengumpulan Data Teknis.

Pada tahapan ini dilakukan pengumpulan data teknis untuk meninjau langsung ke lokasi proyek untuk mengetahui bagaimana kondisi proyek tersebut di lapangan. Adapun jenis-jenis data yang di gunakan adalah data yang di dapat dari tinjauan literatur terkait perencanaan pondasi yang sesuai dengan kondisi di lapangan.

D. Data Sekunder.

Data sekunder merupakan data pendukung yang dipakai dalam proses pembuatan dan penyusunan laporan tugas akhir ini. Metode pengumpulan data sekunder ini meliputi Metode Pustaka (Literatur), Gambar struktur bawah Gedung Fakultas Teknik, RAB proyek.

\subsection{Pengolahan Data}

Data yang sudah terkumpulkan akan diolah untuk mendapatkan hasil akhir yang menjadi tujuan penelitian ini. Data yang akan diolah sebagai berikut :

A. Gambar Rencana Struktur Bawah.

Pada gambar rencana ini akan didapatkan hasil yaitu perhitungan pembebanan untuk Beban Mati dan Beban Hidup. Yang nantinya akan dilanjutkan untuk perumusan berikutnya.

B. Data Hasil Penyelidikan Tanah.

Pada data hasil penyelidikan tanah ini akan digunakan sebagai perhitungan daya dukung tanah tiang pancang, pengolahan tersebut akan didapatkan sebagai berikut : Hasil tes sondir berupa table, Daya dukung tiang ijin tunggal, Daya dukung ijin tiang kelompok, Kapasitas Daya Dukung Tiang, Perhitungan Pile Cap 


\subsection{Bagan Alur Penelitian.}

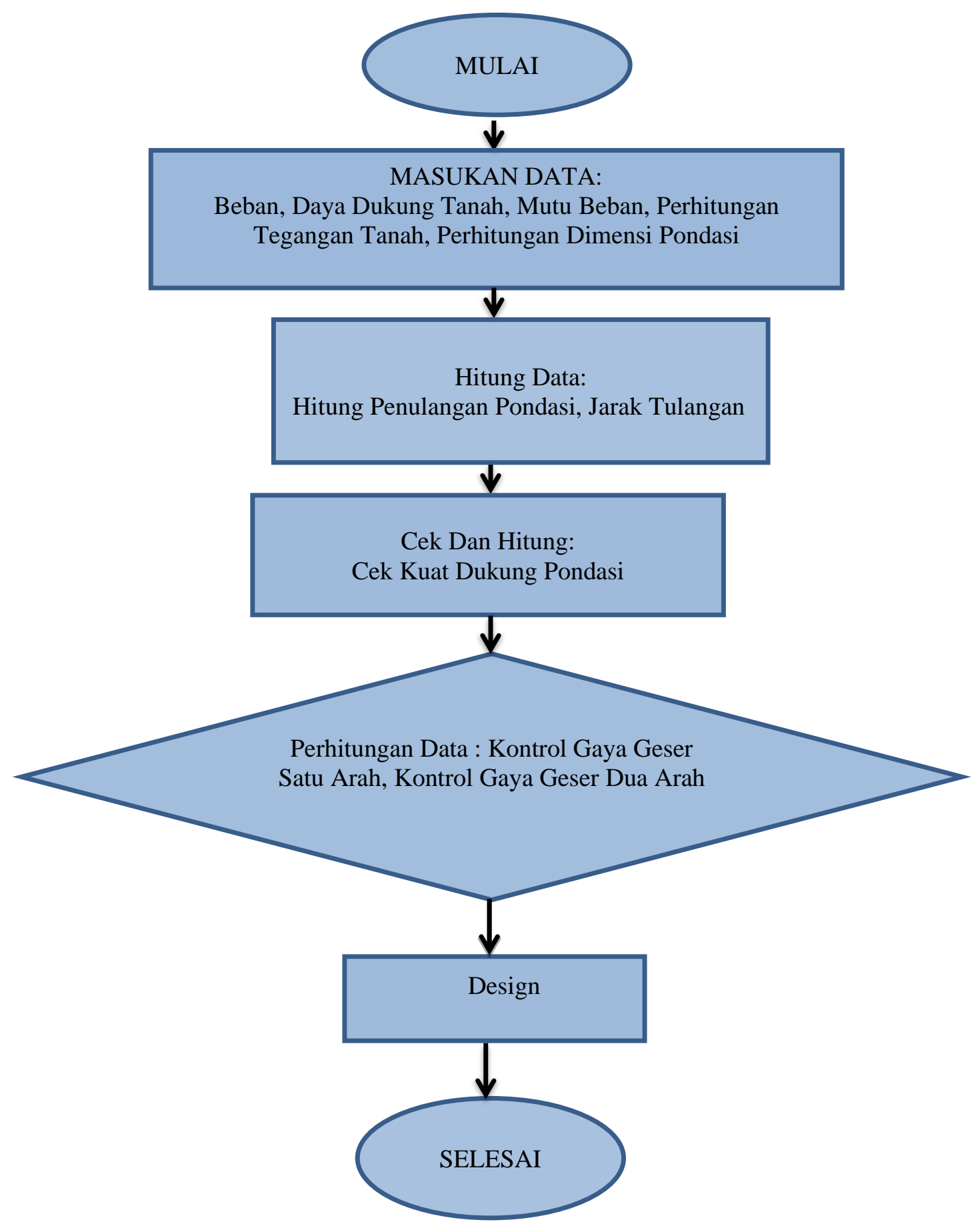

Sumber : Alur Penelitian.

Gambar 1. Diagram Alur Penelitian. 


\section{HASIL DAN PEMBAHASAN}

\subsection{Data Sondir.}

Tabel 1. Data Sondir.

\begin{tabular}{|c|c|c|c|c|c|c|}
\hline $\begin{array}{l}\text { Kedalaman } \\
\text { (M) }\end{array}$ & $\begin{array}{l}\text { Hambatan } \\
\text { Ujung } \\
\text { (qc) } \\
(\mathrm{Kg} / \mathrm{Cm})\end{array}$ & $\begin{array}{c}\text { Jumlah } \\
\text { Perlawanan } \\
\text { (qs) } \\
(\mathrm{Kg} / \mathrm{Cm})\end{array}$ & $\begin{array}{c}\text { Hambatan } \\
\text { Lekat } \\
\left(\mathrm{Kg} / \mathrm{cm}^{2}\right)\end{array}$ & $\begin{array}{c}\text { Hambatan } \\
\text { Pelekat } \\
\left(\mathrm{Kg} / \mathrm{Cm}^{2}\right)\end{array}$ & $\begin{array}{c}\text { J.H.P } \\
\text { Pelekat } \\
\left(\mathrm{Kg} / \mathrm{Cm}^{2}\right)\end{array}$ & $\begin{array}{l}\text { Hambatan } \\
\text { Setempat } \\
\left(\mathrm{Kg} / \mathrm{Cm}^{2}\right)\end{array}$ \\
\hline 0,00 & 0 & 0 & 0 & 0 & 0 & 0 \\
\hline 0,20 & 0 & 5 & 5 & 10 & 10 & 0.5 \\
\hline 0,40 & 2 & 5 & 3 & 6 & 16 & 0.3 \\
\hline 0,60 & 2 & 5 & 3 & 6 & 22 & 0.3 \\
\hline 0,80 & 2 & 5 & 3 & 6 & 28 & 0.3 \\
\hline 1,00 & 5 & 10 & 5 & 10 & 38 & 0.5 \\
\hline 1,20 & 5 & 10 & 5 & 10 & 48 & 0.5 \\
\hline 1,40 & 5 & 10 & 5 & 10 & 58 & 0.5 \\
\hline 1,60 & 5 & 10 & 5 & 10 & 68 & 0.5 \\
\hline 1,80 & 5 & 10 & 5 & 10 & 78 & 0.5 \\
\hline 2,00 & 10 & 10 & 5 & 10 & 88 & 0.5 \\
\hline 2,20 & 10 & 10 & 5 & 10 & 98 & 0.5 \\
\hline 2,40 & 10 & 20 & 10 & 20 & 118 & 1 \\
\hline 2,60 & 10 & 20 & 10 & 20 & 138 & 1 \\
\hline 2,80 & 30 & 40 & 10 & 20 & 158 & 1 \\
\hline 3,00 & 40 & 50 & 10 & 20 & 178 & 1 \\
\hline 3,20 & 40 & 50 & 10 & 20 & 198 & 1 \\
\hline 3,40 & 40 & 50 & 10 & 20 & 218 & 1 \\
\hline 3,60 & 40 & 50 & 10 & 20 & 238 & 1 \\
\hline 3,80 & 40 & 50 & 10 & 20 & 258 & 1 \\
\hline 4,00 & 40 & 50 & 10 & 20 & 278 & 1 \\
\hline 4,20 & 40 & 50 & 10 & 20 & 298 & 1 \\
\hline 4,40 & 45 & 70 & 25 & 50 & 348 & 2.5 \\
\hline 4,60 & 45 & 70 & 25 & 50 & 398 & 2.5 \\
\hline 4,80 & 45 & 70 & 25 & 50 & 448 & 2.5 \\
\hline 5,00 & 65 & 95 & 30 & 60 & 508 & 3 \\
\hline 5,20 & 70 & 100 & 30 & 60 & 568 & 3 \\
\hline 5,40 & 80 & 110 & 30 & 60 & 628 & 3 \\
\hline 5,60 & 80 & 110 & 30 & 60 & 688 & 3 \\
\hline 5,80 & 85 & 120 & 35 & 70 & 758 & 3.5 \\
\hline
\end{tabular}

Sumber : Data Uji Sondir Lapangan. 


\subsection{Perhitungan Daya Dukung Tiang Tunggal}

Tabel 2. Kebutuhan Pondasi Strauss Pada Tiap - Tiap Portal.

\begin{tabular}{|c|c|c|c|c|}
\hline Portal & $\begin{array}{c}\text { Beban (PU) } \\
(\mathrm{KN})\end{array}$ & $\begin{array}{c}\text { Momen } \\
\text { (KN.M) }\end{array}$ & $\begin{array}{c}\text { Dayang Dukung } \\
\text { Strauss (KN) }\end{array}$ & $\begin{array}{c}\text { Kebutuhan } \\
\text { Strauss (bh) }\end{array}$ \\
\hline $\mathrm{M}-9$ & 716,387 & 34,230 & 153,9438 & 5 \\
\hline $\mathrm{M}-10$ & 998,489 & 20,297 & 153,9438 & 7 \\
\hline $\mathrm{M}-11$ & 995,204 & 27,293 & 153,9438 & 7 \\
\hline $\mathrm{M}-12$ & 834,136 & 28,096 & 153,9438 & 6 \\
\hline $\mathrm{M}-14$ & 716,493 & 37,043 & 153,9438 & 5 \\
\hline & & & & \\
\hline & & & & \\
\hline
\end{tabular}

Sumber : Analisa Kebutuhan Pondasi Strauss Pada Tiap - Tiap Portal.

$\mathrm{Nb}$ : Untuk portal M-10 dan M-11 pembuatan pile cap nya digabung, karena jarak antar portalnya terlalu kecil, sehingga kebutuhan tiang straussnya menjadi 13 buah. 


\subsection{Perhitungan Pile Cap.}

A. Kontrol Gaya Geser Satu Arah.

$$
\mathrm{Vu}=\sigma \times \mathrm{LxG}^{\prime} \text {. }
$$

Dengan Rumus $\mathrm{G}^{\prime}$ :

$$
\begin{aligned}
\mathrm{G}^{\prime} & =L-\left(\frac{L}{2}+\frac{\text { Lebar Kolom }}{2}+d\right) . \\
& =5800-\left(\frac{5800}{2}+\frac{600}{2}+450\right) . \\
& =2.150 \mathrm{~mm} .
\end{aligned}
$$

Rumus d (tebal efektif plat) :

$$
\mathrm{d} \quad=500-50=450 \mathrm{~mm} \text {. }
$$

Sehingga :

$$
\begin{aligned}
\mathrm{Vu} & =36,76 \times 5,8 \times 2,15 . \\
& =458,40 \text { Ton. }
\end{aligned}
$$

B. Kontrol Gaya Geser Dua Arah.

$$
\begin{aligned}
\mathrm{Vu} & =\mathrm{o}^{\prime}\left(\mathrm{L}^{2}-\mathrm{B}^{\prime 2}\right) . \\
& =36,76\left(5,8-\mathrm{B}^{\prime 2}\right) .
\end{aligned}
$$

\begin{tabular}{|c|c|c|c|c|c|c|c|}
\hline \multirow{3}{*}{ Kolom } & \multirow{2}{*}{$\phi \mathrm{Mu}$} & \multirow{2}{*}{$\mathrm{Mu}$} & \multirow{3}{*}{$\phi \mathrm{Mn}>\mathrm{Mu}$} & \multicolumn{4}{|c|}{ Tulangan Pile Cap } \\
\hline & & & & $\mathrm{d}$ & & $\mathrm{s}$ & As \\
\hline & Kgm & Kgm & & $\mathrm{mm}$ & $\mathrm{n}$ & $\mathrm{mm}$ & $\mathrm{mm}^{2}$ \\
\hline K1 & 150098 & 12791 & (OKE) & 16 & 5 & 175 & 1608 \\
\hline
\end{tabular}

Dengan Mencari penampang kritis (B') :

$$
\begin{aligned}
\mathrm{B}^{\prime} & =36,76+2\left(\frac{1}{2}\right) \times 45 . \\
& =81,76 \mathrm{Cm} \ldots \ldots \ldots \ldots \ldots . . \text { Dilakukan pembulatan }=82 .
\end{aligned}
$$

Sehingga :

$$
\begin{aligned}
\mathrm{Vu} & =36,76\left(5,8^{2}-0,82^{2}\right) . \\
& =1.211,98 \text { Ton. }
\end{aligned}
$$

\subsection{Hasil Tulangan Pile Cap.}

Tabel 3. Hasil Tulangan pile cap.

Sumber : Analisa Perhitungan Tulangan Pile Cap.

Sehingga :

$$
\varphi \mathrm{Mn}=150,098 \mathrm{Kn} \cdot \mathrm{M}>\mathrm{Mu}=127,01 \quad \mathrm{Kn} \cdot \mathrm{M} \ldots \ldots \ldots .(\text { Oke })
$$




\section{KESIMPULAN}

Setelah melakukan analisa daya dukung pondasi tunggal ataupun kelompok bisa kita disimpulkan bahwa:

1. Dari hasil hitungan yang di lakukan pembebanan sebelum merencanakan pondasi tiang pancang, beban yang diterima pondasi tiang pancang sebesar $\mathrm{Qu}=231$ Ton

2. Dari perhitungan sondir yang di lakukan kedalaman tanah keras di Gedung C Universitas Kadiri mencapai kedalaman 5,6 m, pada kedalaman pondasi tersebut mampu menahan beban gedung yang di rencanakan.

3. Dari hasil perhitungan ke tiga metode berikut ini adalah hasilnya :

- Metode trofimankove.

- Perhitungan daya dukung tiang tunggal diameter $35 \mathrm{Cm}=43,25$ Ton.

- Perhitungan daya dukung kelompok $=248,22$ Ton dengan jumlah tiang 8 tiang.

- Metode mayerhoff.

- Perhitungan daya dukung tiang tunggal diameter $35 \mathrm{Cm}=52,85$ Ton .

- Perhitungan daya dukung kelompok $=257,93$ Ton dengan jumlah tiang 7 tiang .

- Cara umum.

- Perhitungan daya dukung tiang tunggal diameter $35 \mathrm{Cm}=38,21$ Ton.

- Perhitungan daya dukung tiang kelompok =232,82 Ton dengan jumlah 9 tiang.

4. Dari perhitungan ketiga metode didapat hasil yang lebih efisien yaitu perhitungan dengaan metode mayerhoff :

- Dengan syarat Pmaks < Pall didapat dalam perhitungan tiang tunggal pada metode cara umum $=38,21$ dengan jumlah tiang tunggal yang mendekati pada satu pile cap adalah 9 tiang didapat Pall dari perhitungan tiang kelompok $=232,82$

- Maka disimpulkan Pmaks $<$ Pall $=231$ ton $<232,82$.

\section{SARAN}

Dari Hasil perhitungan perencanaan diatas penulis memberikan saran pada perhitungan tiang pancang (pile cap) harus dilakukan perhitungan kontrol kelompok tiang serta kontrol gaya lateral supaya konstruksi pondasi yang direncanakan mampu mundukung beban beban yang di rencanakan.

\section{UCAPAN TERIMA KASIH}

Penulis ingin berterima kasih kepada Universitas Kadiri, khususnya Fakultas Teknik yang telah memberi kesempatan untuk melakukan penelitian dan menyusun artikel ilmiah. 


\section{DAFTAR PUSTAKA}

[1] K. Prayogo and H. Saptowati, "Penyelidikan struktuur dan karakteriistik tanah untuk desain Pondasi Iridiatir Gamma kapasitas 2 MCi,” J. Perangkat Nukl., vol. 10, no. 1, pp. 30-49, 2016.

[2] F. F. Andi Yusti, "Analisis Daya Dukung Pondasi Tiang Pancang Diverifikasi Dengan Hasil Uji Pile Driving Analyzer Test Dan Capwap," Fropil, vol. 2, no. 1, pp. 19-31, 2014.

[3] Y. C. BAGUS ANGGORO WIRATMOKO ,SIGIT WINARTO, "PERENCANAAN PONDASI TIANG PANCANG GEDUNG KETAHANAN PANGAN NGANJUK (FOUNDATION PLANNING OF NGANJUK FOOD SECURITY BUILDING) BAGUS," Jurmateks, vol. 2, no. 1, pp. 1-9, 2019.

[4] B. J. G. Hamdil Khaliesh, "PONDASI TIANG TONGKAT SEBAGAI ADAPTASI KONSTRUKSI LAHAN GAMBUT DI KALIMANTAN BARAT," in SEMINAR NASIONAL SCAN\#4:"Stone, Steel, and Straw" Building Materials and Sustainable Environment, 2013, pp. 1-10.

[5] M. R. Agil Faruha, "ANALISA PERHITUNGAN DAYA DUKUNG PONDASI TIANG PANCANG DIBANDINGKAN DENGAN DAYA DUKUNG HYDRAULIK JACKING SYSTEM DAN PILE DRIVING ANALYZER (PDA) TEST PADA PROYEK PEMBANGUNAN GEDUNG PERPUSTAKAAN SEKOLAH TINGGI AGAMA ISLAM NEGERI KEDIRI," Rekayasa Tek. SIipil, vol. 2, no. 2, p. 18, 2018.

[6] A. I. Candra, A. Yusuf, and A. R. F, "Studi Analisis Daya Dukung Pondasi Tiang Pada Pembangunan Gedung Lp3M Universitas Kadiri,” J. CIVILA, vol. 3, no. 2, pp. 166-171, 2018.

[7] T. R. EkoYuliawan, "Analisis Daya Dukung dan Penurunan Pondasi Tiang Berdasarkan Pengujian SPT dan Cyclic Load Test,” J. Konstr., vol. 9, no. 2, pp. 1-13, 2018.

[8] W. Jawat, "Metode Pelaksanaan Pekerjaan Pondasi (Studi: Proyek Fave Hotel Kartika Plaza)," PADURAKSA, vol. 4, no. 2, pp. 22-34, 2017.

[9] S. S. Purwanto, "KONSTRUKSI PONDASI SARANG LABA-LABA ATAS TANAH DAYA DUKUNG RENDAH BANGUNAN BERTINGKAT TANGGUNG," Tek. Sipil, vol. 12, no. 1, pp. 51-60, 2012. 
[10] Y. Iskandar and K. Lahji, "Kearifan Lokal dalam Penyelesaian Struktur dan Konstruksi Rumah Rakit di Sungai Musi Palembang," J. Ilm. Online Local Wisdom, vol. 2, no. 2, pp. $37-45,2010$.

[11] A. I. Candra, "ANALISIS DAYA DUKUNG PONDASI STRAUSS PILE PADA PEMBANGUNAN GEDUNG MINI HOSPITAL UNIVERSITAS KADIRI," Ukarst, vol. 1, no. 1, pp. 63-70, 2017.

[12] E. S. Randyanto, "Menggunakan Metode Statik Dan Calendring Studi Kasus : Proyek Pembangunan Manado Town Square 3," Sipil Statik, vol. 3, no. 9, pp. 631-643, 2015.

[13] W. A. N. Aspar, "PERILAKU TIANG BOR PENOPANG INFRASTRUKTUR PADA TANAH LUNAK AKIBAT BEBAN STATIK," J. Sains dan Teknol. Indones., vol. 12, no. 3, pp. 166-173, 2010.

[14] F. E. Yulianto and T. J. Irwanto, "ANALISA PENGGUNAAN PONDASI STROUSS DAN PONDASI TELAPAK DITINJAU DARI BIAYA PELAKSANAANNYA PADA PEMBANGUNAN GEDUNG DUA LANTAI,” in Seminar Nasional III Teknik Sipil 2013 Universitas Muhammadiyah Surakarta, 2013, pp. 386-417.

[15] A. I. Candra, H. Wahyudiono, S. Anam, and D. Aprillia, "KUAT TEKAN BETON Fc' $21,7 \mathrm{MPa}$ MENGGUNAKAN WATER REDUCING AND HIGH RANGE ADMIXTURES," J. CIVILA, vol. 5, no. 1, 2020.

[16] S. Susanto, "PERBANDINGAN FUNGSI KEANGGOTAAN TIPE SEGITIGA DAN TIPE G-BELL TERHADAP ANALISIS RISIKO," Ukarst, vol. 3, no. 2, pp. 57-67, 2019.

[17] N. M. T. Dewi, "TANGGUNG JAWAB HUKUM ARSITEK TERHADAP KONSTRUKSI BANGUNAN YANG TIDAK SESUAI DENGAN PERENCANAA," Krettha Dyatmika, vol. 16, pp. 41-49, 2019.

[18] M. Yusuf, "Penyelesaian sengketa akibat kegagalan bangunan dalam perjanjian kerja konstruksi," Universitas Ilam Indonesia, 2008.

[19] A. R. Rahmad Ilyas Kurniawan, "PERENCANAAN PONDASI TIANG (Studi Kasus HOTEL MERDEKA TULUNGAGUNG),"Jurmateks, vol. 2, no. 1, pp. 1-9, 2019.

[20] "STANDAR PERENCANAAN KETAHANAN GEMPA UNTUK STRUKTUR BANGUNAN GEDUNG SNI-1726-2002." Pusat Penelitian dan Pengembangan Teknologi Permukiman, Bandung, 2002. 